\title{
Lexical Formation Rules and Chatting Language Online in English*
}

\author{
Li Ruan \\ School of Foreign Languages, Qingdao University of Science \& Technology, Qingdao266061, China \\ Email: t96750@yahoo.com.cn
}

\begin{abstract}
Nowadays, exploring the lexical formation rules of chatting language online is a popular linguistic subject. On one hand, online language is a new way of communication and more and more new words and expressions are created. On the other hand, it still follows the traditional ways of lexical formation rules in some ways.
\end{abstract}

Index Terms - lexical formation, chatting language online, abbreviation, semantic change, coined word

On the Internet there are innumerable new words coming and dying. The Internet provides a space for individuals to freely create new words for only one particular occasion. What is needed is just a brief explanation about the meaning of the new word the first time you use it. The rapid spread of information on the Internet makes those new words well-known among netizens.

Today, exploring and probing the lexical formation rules of chatting language online is a popular linguistic subject. New as it is, chatting language online follows the traditional way of lexical formation. As David Crystal puts it, "From their construction, they are not really new at all. Even the weirdest neologisms are based on a small set of established principles." (Crystal, 2001,p.67) So according to the commonly used ways of lexical formation, there are: invention/coinage, compounding, blending, abbreviation, acronyms, metanalysis, back-formation, conversion, analogical creation, borrowing, and semantic change. The following part of the section will illustrate whether the lexical change of the chatting language online in English will follow these formation rules.

\section{ABBREVIATION AND ACRONYM}

"Abbreviations (and acronyms) have long been part of the written language tradition, appearing both in hand written manuscripts and print. Their most common function in both off-line writing and CMC is to conserve energy and/or space." "There is a second socially-based motivation for incorporating abbreviations into CMC messages: to indicate one's membership among net work cognoscenti."(Baron, 2003, p. 21)

From the above statement on abbreviation and acronyms, it can be concluded that the application of the two methods is mainly for two purposes: one is for efficiency and convenience; the other is for identifying one's group membership. Like the use of slang in face-to-face speech or written language, abbreviation and acronyms are a way of indicating group membership.

\section{A. Abbreviation}

Abbreviation is also called clipping. That is, a new word is created by cutting the final part, the initial part or cutting off both the initial and the final part with only the middle part left. (Zhuanglin Hu, 1988, p. 178). In online chatting, clipping is also an important way of word formation. There are several common types of clipping in chatting language online.

1. Front clipping: the deletion occurs at the beginning of the word
$\mathrm{u}$--- you ur --- your m:male am --- $\mathrm{m}$ n --- in $\mathrm{k} \mathrm{---} \mathrm{ok}$
$<$ CRUNK_586> r u sure? ------ Are you sure?
<wondererinhoust> 40/ $\underline{\mathrm{m}}$ houston ------ I am 40, male and live in Houston.
JIMMY: 21 / $\mathrm{m}$------ I am 21, male.
JIMMY: and u ? ------ And you?
monkey_brat0016: do $\underline{u}$ want to talk ------ Do you want to talk?
johnson4luv2009: $\underline{u}$ there ------ Are you there?
2. Middle clipping: the deletion occurs at the middle of the word
ft: faint b/c: because r: are wat: what
$<$ Gangstar-586> anybody wanna chat in pvt ------ Does anybody want to chat in private?
$<$ DarK_HerrOr $>$ ur 15 ---- You are 15.
<suger_125> what $\mathrm{r}$ u peoples talking about? ---- What are you talking about?

\footnotetext{
* This essay is financed by the Social Science and Humanity Research Project of Qingdao University of Science and Technology in 2010, Number10XC24
} 
$<$ Gangstar-586> wat <censored> ------ What?

3. End clipping: the deletion occurs at the end of the word.

b --- be $\mathrm{g}$--- gee $\mathrm{o}$--- oh $\mathrm{g}$---grin $\mathrm{s}$--- smile

4. Middle and end clipping: the deletion occurs in the middle and at the end of the word.

pvt: private b/t: between pls: please ez --- easy

\section{B. Acronym}

Acronym is a very general word in the dissertation. In a narrow sense, it is "made up from the first letters of the name of an organization"(Zhuanglin Hu, 1988,p. 178), such as: WB (World Bank), CIA (Central Intelligence Agency). In a broader sense, it is formed by picking the initial letters of words, phrases or even sentences.

In the Internet chat rooms, acronyms are one of the most remarkable features, which save a great deal of energy and time. It is no longer restricted to word or short phrases, but can be sentence long: WDYS (What did you say?). But on the whole, acronyms of phrases constitute a large proportion.

Most chat-room participants are familiar with some of the basic acronyms, e.g.

BRB --- be right back IMHO --- in my humble opinion

BTW --- by the way IRL --- in real life

LOL --- laughing out loud ROTFL --- rolling on the floor laughing

asl --- age, sex, and location

Here is an example copied from the icq chat room:

monkey_brat0016: bye jimmy asl ---- Jimmy, what is your age, sex, and location.

JIMMY: 21 / $\mathrm{m}$---- I am 21 and male.

JIMMY: and u ? ---- Are you?

Since most people in the chat rooms are unfamiliar with each other. The questions about one's identification are frequently asked. As a result of that, 'asl' will bring chatter more convenience to do so.

Less well-known acronyms appear in the chatting messages sent by restricted groups of users. For instance, "pos" (parent over shoulder) is used by some American teenagers who are in the process of chatting to a friend when a parent walks into the room, and the chatter wants to alert the recipient that open chatting is no longer possible.

In this section, acronyms appearing in English chat rooms are roughly classified into four groups:

1. Individual words can be reduced to two or three letters, like:

pls --- please pvt --- private wat --- what ppl --- people abt --- about

2. Phrases may be reduced to a sequence of initial letters, which fall into three groups:

a. Reduced noun phrases:

BF --- boy friend GF --- girl friend POV --- point of view

FAQ --- frequently asked questions ASL --- age, sex, and location

OL --- old lady OM --- old man FOAF --- friend of a friend

b. Reduced verbal phrases:

ROTFL --- rolling on the floor laughing

LOL --- laughing out loud HAND --- have a nice day

BRB --- be right back WB --- welcome back

GA --- go ahead DTRT --- do the right thing

c. Reduced prepositional phrases and others:

ASA ---: as soon as possible AAMOF --- as a matter of fact

BTW --- by the way IOW --- in other words

IRL --- in real life OTOH --- on the other hand

AYOR --- at your own risk FTTT --- from time to time

d. Reduced adjective phrases:

VG --- very good BC --- be cool

3. Sentences can also be reduced to a series of initial letters:

SWDYT --- So what do you think?

PCM --- Please call me.

BRB --- Be right back.

BBL --- Be back later.

HHOJ --- Ha, ha, only joking.

DIKY --- Do I know you?

There is another kind of acronyms using letters to replace the same pronunciation. The most typical example is letter 'C' which is often used to replace 'see' or 'seek', such as in the following examples:
CU --- see you CUL --- see you later
ICQ --- I seek you OIC --- oh, I see
IC --- I see CYO --- see you online

The great number of acronyms in chat-room talks shows that the creation of acronyms follows a principle of economy. That is to achieve the maximum result with the minimum amount of effort, which means that " the short form is preferred to a longer or more involved one" (Zhuanglin Hu, 1988, p.21) This fully explains the role played by acronyms, which are much easier and more time-saving than complete words, phrases and sentences. The emergence of numerous acronyms shows the creativity and wisdom of chat-room participants.

4. Combination of acronyms and special symbols 
There are some other ways to express your feelings uniquely. For example, the combination of acronyms and special symbols can be used to create a vivid picture in chatters' mind. For instance, you can find the following ways of expression in a chat room:

$$
\begin{aligned}
& \text { * } \mathrm{K}^{*} \text {--- Kiss } \quad * \mathrm{H}^{*} \text {--- Hug } \quad * \mathrm{~W}^{*} \text {--- Wink } \\
& \text { =w }=\text {--- whatever } \quad{ }^{*}{ }^{*} \text {--- Giggle } \quad \text { C\&G --- Chuckle and grin } \\
& \text { II. Semantic Change }
\end{aligned}
$$

Change in the meanings of words is known as semantic change and can be viewed as part of the more general phenomenon of lexical change, or change in a language's vocabulary, such as the word "mouse" is originally a noun, which online refers to " a hand-held, button-activated input device that when rolled along a flat surface directs an indicator to move correspondingly about a computer screen, allowing the operator to move the indicator freely, as to select operations or manipulate text or graphics", which is quoted from American Classic Dictionary in Kingsoft dictionary .

Sometimes, in online chat, a new meaning is added to an old word. Change of traditional meaning to form new words greatly expanded the traditional lexicon as shown in the following.

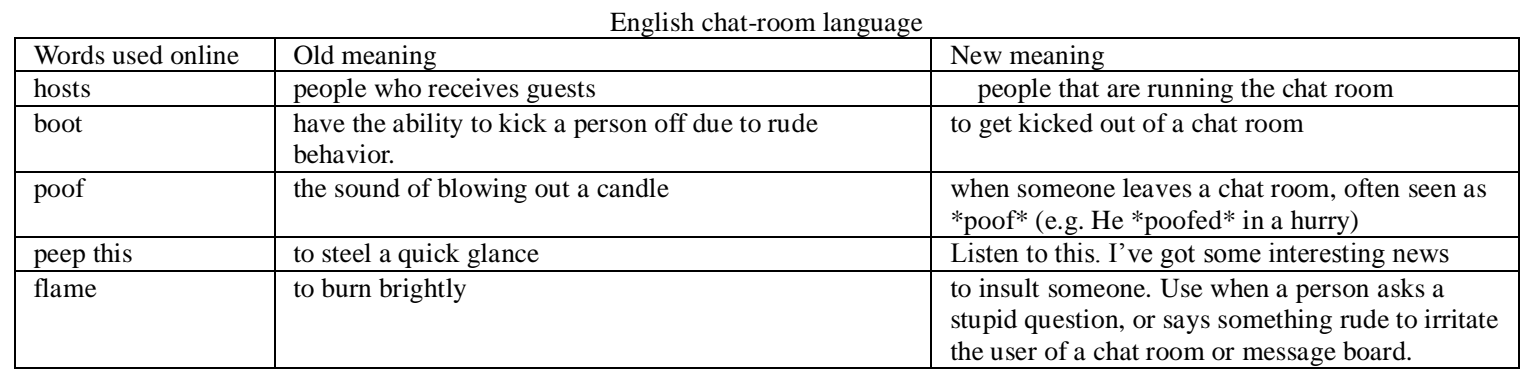

\section{INVENTION / COINAGE}

Invention or coinage refers to the creation of new words. A word is a broad term in this dissertation. It is a basic unit of vocabulary and is interpreted as a combination of a form with a meaning. Chatting language online is new and original, as a result of the frequent occurrence of numerous coined words (newly created words).

Since the Internet is dynamic and active in human life, many new lexical items come directly from the activities online. "Media texts are fruitful areas for this kind of linguistic playfulness". (Thornborrow, 1998, p.189) Chatting language online, as a new medium language, has put lexical creativity into full play. In a chat room, language can be shaped in different ways by being played with, taken apart and put back together. The Internet enables thousands of netizens to see the coined word at the same time. Therefore, coined words in chat rooms spread rapidly and widely than traditional media. There are some underlying rules as to the word creation in the chatting language online.

\section{A. Capitalization and Bold Forms}

1. Capitalized and Bold Forms Standing for Loud Volume

Capitalized and bold forms of words are often used for expressing emphasis or loud volume.

In casual online chats, the use of capitalized and bold words is the common way of marking emphatic stress or increased volume. In chat rooms, messages specially written in such forms are considered to be 'shouting'. Here is an example, in which the powerful feelings and anger are expressed by 'shouting' IN CAPITAL: TOO MUCH USE OF CAPITALS IS BAD MANNERS.

The talk below is collected from an ICQ chat room. The first part of the talk shows that <sunshine> is seeking for someone from German. In order to catch others' attention, she unusually uses words in capitalized form. It gives us a feeling that she/he is trying to speak loud in a quite "noisy" room.

$<$ LULI $>$ 's capitalized words also serves as the same function.

$<$ DAZ $>$ hi room

$<$ DAZ $>$ hi ester

$<$ sunshine> IS ANYBODY FROM GERMAN HERE?

$<$ jamesX> morning

$<$ LULI $>$ I AM LULI OF THE ARGENTINA..

$<$ MommasBoy> Hiya

The example below from a yahoo chat room, offers us another form for emphasis and loud volume, that is, bold words.

monkey_brat0016: ok bye yall

monkey_brat0016: have a good day

monkey_brat0016: happy early easter 
In this dissertation, words are defined as a combination of form and meaning, and the capitalized and bold forms which represent loud volume, do have their graphic form and semantic value (fore expressing strong emotion or loud voice). Thus, in the online chat rooms, they are indeed as expressive as traditional words. Though their forms are strange and far away from the traditional word forms in our mind, they are included in the category of newly created words in online chat rooms.

2. Ignoring Initial Capitalization is Not a Way of Word Coinage

With relatively low frequent use of capital letters in sentence initials, most chatting language online disobeys the traditional standard language rules. By observing the dialogues from some chat rooms, it is not difficult to find out that only the dialogues in some professional chat rooms show a relatively better use of initial capitalization. In other more casual chat rooms, it is a common phenomenon that capitalization is ignored. This is probably due to the speaker's habit of saving energy and time. In the following talks which are copied from the ICQ chat rooms, there is not a capitalized word at all:

$<$ Gangstar-586> asl ya'll

$<$ vinniethepooh> only if you dont bring your boyfriend angel

$<$ CRUNK_586> yes i am

$<$ DarK_HerrOr> ur 15

<angeldust78> lol:)

$<$ CRUNK_586> r u sure?

$<$ DarK_HerrOr $>$ maybe 16

$<$ vinniethepooh> or are you still with him?

$<$ Vash $>/ !$ angeldust78 /!! hi hun

$<$ DarK_HerrOr $>$ stop dat

$<$ angeldust78> yeh sorry i'm back

<suger_125> hay dark_HerrOr

$<$ vinniethepooh> wb angel

$<$ angeldust78> thx hun

*DarK_HerrOr waves to say hey 2 all

Why is capitalization seldom used in real-time chatting online? Probably, it is due to the "save a keystroke" principle. Usually, most of chatting participants try to send out his or her messages as quickly as possible, in case he or she is interrupted by others. Capital letters are not considered necessary, since people can still understand what others are talking about without capitalization. So it is considered a waste of time to press a "CapsLock" or "shift" key to type a capital letter.

However, no initial capitalization as a way to "save a keystroke", does not convey any additional meaning to other people. Therefore, it is not considered as a way of word formation.

\section{B. Deviant Use of Punctuation Marks}

The original function of punctuation is to help readers make clear understanding of the structure and meaning of a sentence. The deviant use of punctuation is one of the remarkable characteristics of chatting language online, such as the punctuation marks (together with keyboard characters) being used in emoticons, about which there is a detailed explanation in the emoticon section. In this part of the study, we will talk about the repetition or overuse of some particular punctuation marks, like question marks and exclamation, and the omission of some originally necessary punctuation.

1. Expressiveness of Overused Punctuation Marks

The overuse of the punctuations here mainly refers to the repetition of the punctuations at the end of a sentence.

Although in real-time chatting punctuation is often unused, there are some punctuation marks being overused under certain circumstances (like the question mark and exclamation mark):

no more!!!!! what???????????? sooooooooo??????? whohe????

Overuse of those marks mainly has two reasons:

a. Expressing strong emotions and feelings, such as feeling puzzled, excited, astonished, or even gloomy.

Expressiveness and emphasis are considered as the major reasons as to inputting such repeated punctuation marks. It is an exaggerated way to express the sender's doubts as in the case of the question mark, and the senders' surprise as in the overused exclamation marks. The repetition of punctuations like question marks and exclamation marks is expressive, and indeed conveys a certain degree of meaning, as illustrated in the sample:

$<$ CRUNK_586> im on spring break!!!!!!!!!!

$<$ Gangstar-586> <censored> all!!!

Chat room talks " lacks the facial expressions, gestures, and conventions of body posture and distance which are so critical in expressing opinions and attitude and in moderating social relationships,"(Crystal, 2001,p. 36) So the adoption of repeated punctuation marks for expressing emotions are giving fresh semantic value to the chat-room talks and lead to the introduction of emoticons or smileys.

b. Sometimes, overuse of punctuation marks also reflects the length of time that the relevant key is held down. In this case, the exact number of the repeated punctuation marks has little to do with the meaning, and it will not be considered 
a part of lexical category.

2. Omission of Punctuation is Unexpressive

$<$ angeldust78> lol

$<$ vinniethepooh>i c

$<$ douglas $>$ hi room

<angeldust78> it should b poking its tongue out

$<$ vinniethepooh> what will you do for a job

$<$ angeldust 78> yes hun

$<$ vinniethepooh> if you get out of the biz

<angeldust78> when

<vinniethepooh> after real estate

As illustrated in the sample above, those sentences sent by different persons do not have a single punctuation at all.

The "save keystroke" principle is the major reason for most netizons to omit punctuations in their messages, especially when it will save more than one keystroke (such as: two keystrokes are needed when typing question marks).

The omission of punctuation is just a time-saving stroking method. It does not convey any extra meaning to the other chatters, so it is not expressive. As a result of that, according to the related lexical theories, omission of punctuation is not considered as part of lexicon.

\section{The Future of Chatting Language OnLine}

Since language reflects social environment and social change, it is not surprising that the social innovation (such as the development of information technology) will bring a great impact on the way of communication. Internet is a dynamic, creative system, so chatting language online is also an evolving language variety.

Internet users are exploring more and more ways of expression to chat online in order to fit different occasions. There are a lot of new words emerged in the Internet chat rooms and only time can tell which one will last long, and which one will be quickly forgotten. It is hard to predict the future change of chatting language online. Therefore, it seems to be wise to warn the readers that some chatting words and expressions are easy to be out of date.

What is clear is that a number of present chatting lexicons on the Internet are beginning to penetrate into traditional spoken and written language. Since chatting language online "is physically a written medium, it is not surprising that some of the linguistic conventions common in more informal types ... are finding their way into traditional off-line writing. Abbreviations and acronyms, devil-may-care spellings, are increasingly showing up in student written composition." (Baron, 2003, p. 24) Taking spoken language as an example, some American adolescents, in face-to-face conversation, uses such words as "We were all ROTLing when the teacher walked in" (Baron, 2003, p. 23) to mean that "we were all rolling on the floor laughing".

Historically, it is common for new terms or concepts deriving from developments in technology to find their way into traditional off-line language. Chatting language online is beginning to have similar impact on traditional formal language. The new, informal linguistic form of language is extending the range of traditional language. Online chatters have been continuously creating and introducing new chatting words and expressions into traditional established vocabulary. Formal standard language will be viewed in a completely new way, by virtue of the existence of chatting language online. Therefore, in the future, further research on semeiology, pragmatics, comparative study, etc, need be done in this new and challenging field.

\section{REFERENCES}

[1] Baron, Naomis.(2003).The Stanford Handbook for Language Engineers. Stanford: CSLIP Publications. p.23-24. 59-127.

[2] Crystal, David. (2001). language and the Internet. Cambridge: Cambridge University Press. p.67

[3] Fan Gao. (2004). New Words in Netglish and Characteristic of Word-formation. Journal of Liaoning Technical University (Social Science Edition) 6(5) p.550-552

[4] Min Qin. (2005). On the Characteristics and Formation of Internet English. Journal of Harbin Teachers College (12). p.127-129.

[5] Thornborrow, Joanna, and Shan Wareing. (1998). Patterns in Language: Stylistics for Students of Language and Literature. London: Taylor \& Fancis Limited. p.189.

[6] Zhuanglin Hu. (1988). Linguistics: A Course Book. Beijing : Beijing University Press.p.21, p.178

Li Ruan was born in Jilin,, China in 1976. She received her M.A. degree in linguistics from the Ocean University of China in 2005. She is currently a lecturer in the School of Foreign Languages, Qingdao University of Science and Technology, Qingdao, China. Her research interest is applied linguistics. 